\title{
A categoria utilidade subjacente às tendências em Educação Matemática: discussão a partir da Pedagogia Histórico-Crítica
}

\author{
The utility category subjacent in the Mathematical Education tendencies: a debate from the \\ Historical-Critical Pedagogy \\ La categoría de utilidad subyacente a las tendencias en Educación Matemática: discusión a partir \\ de la Pedagogía Histórico-Crítica
}

\begin{abstract}
Resumo
A presente pesquisa, de cunho bibliográfico, apresenta um debate sobre a categoria utilidade no âmbito da Educação Matemática, em especial no âmbito da Pedagogia Histórico-Crítica. A partir disso, o problema de pesquisa se expressou no seguinte questionamento: como a categoria utilidade é entendida no âmbito da Educação Matemática a partir do prisma da Pedagogia Histórico-Crítica? Assim, o objetivo foi compreender a categoria utilidade no campo de estudos da Educação Matemática, de modo especial, a partir das bases teórico-metodológicas que fundamentam a Pedagogia Histórico-Crítica. No primeiro momento, analisamos a referida tendência e suas possíveis implicações na Educação Matemática. Verificamos que a utilidade não é vista no sentido imediato, mas pela relação que se estabelece entre indivíduo-sociedade-gênero. Desse modo, a referida Pedagogia se contrapõe a outras, de cunho utilitário-pragmatistas, que imputam ao conhecimento matemático uma essência pautada na imediaticidade da vida cotidiana. Por meio desse entendimento, corre-se o risco de transformar a Matemática em uma ciência que resume sua validade por suas meras aplicações práticas imediatas, tornando-as critério de verdade dos conceitos matemáticos. Como implicação, o ensino da Matemática teria como critérios a aplicação e o relacionamento direto com a vida cotidiana dos estudantes. Portanto, consideramos necessário e urgente um debate que se paute na gênese e no desenvolvimento histórico do conhecimento matemático a partir de uma interpretação dialético-materialista. A intenção é instigar as discussões com a finalidade de aprimorar o desenvolvimento da práxis pedagógica que tenha como fundamento uma formação humana omnilateral.

Palavras-chave: Utilidade; Educação matemática; Pedagogia histórico-crítica.
\end{abstract}

\begin{abstract}
The present research, bibliographical nature, sets forth a debate on the category utility in the circle of Mathematics Educations Studies, in special in the Historical-Critical Pedagogy. As from, the research problem emerges from the following question: How is utility category understood in the circle of Mathematics Education Studies from the Historical-Critical Pedagogy views? Thus, the objective was to understand the utility category in the fields of Mathematics Educations Studies, in special, from the theoretical-methodological basis that are underlined in the Historical-Critical Pedagogy. First of all, we analyzed the referred tendency and its possible implications in the Mathematical Education. We checked that the utility is not learned in an immediate way, but by its relation that has its expression as an individual-society-human gender. So, the referred Pedagogy has contraposition with others, with pragmatical and utilities views, which undergoes within a conception that the mathematical knowledge has an essence linked to the immediacies of the current life. Through this understanding, there is a risk in transforming the Mathematics to a science that only incurs into validity because its simple practical immediacies applications, turning them into a true criterion of the math concepts. As implications, the Mathematic teaching has to be as criteria, the application and the direct relationship with the students currently life. Therefore, we understand that is necessary and urgent a debate that, mainly, takes into account the genesis and the historical development of the mathematical knowledge from the dialectical-materialist approach. The intention is to instigate the debate on the objectives and improve the development of the pedagogical praxis which has as foundation in an omni-lateral human formation.
\end{abstract}

Keywords: Utility; Mathematical education; Historical-critical pedagogy. 


\begin{abstract}
Resumen
La presente investigación, de carácter bibliográfico, presenta un debate sobre la categoría de utilidad en el ámbito de la Educación Matemática, en particular, en el ámbito de la Pedagogía Histórico-Crítica. A partir de esto, el problema de investigación se expresó en la siguiente pregunta: ¿cómo la categoría utilidad pública es entendida en el ámbito de la de la Educación Matemática, desde la perspectiva de la Pedagogía Histórico-Crítica? Así, el objetivo fue comprender la categoría de utilidad en el campo de los estudios de Educación Matemática, de manera especial, a partir de las bases teóricas y metodológicas que sustentan la Pedagogía Histórico-Crítica. En un primer momento analizamos la referida tendencia y sus posibles implicaciones en la Educación Matemática. Verificamos que la utilidad no se ve en el sentido inmediato, sino por la relación que se establece entre individuo-sociedad-género. De esta forma, la citada Pedagogía se contrapone a otras, de carácter utilitario-pragmatistas, que imputan al conocimiento matemático una esencia basada en la inmediatez de la vida cotidiana. A través de este entendimiento, se corre el riesgo de transformar la Matemática en una ciencia que resuma su validez en sus meras aplicaciones prácticas inmediatas, convirtiéndolas en el verdadero criterio de los conceptos matemáticos. Como implicación, la enseñanza de la matemática tendría como criterio la aplicación y relación directa con la vida cotidiana de los estudiantes. Por lo tanto, consideramos necesario y urgente un debate que se paute en la génesis y en el desarrollo histórico del conocimiento matemático, a partir de una interpretación dialéctico-materialista. La intención es instigar las discusiones con la finalidad de mejorar el desarrollo de la praxis pedagógica que tenga como fundamento una formación humana omnilateral.
\end{abstract}

Palabras clave: Utilidad; Educación matemática; Pedagogía histórico-crítica.

\title{
1. Introdução
}

A categoria utilidade tem diferentes implicações às finalidades postas à educação, em particular à Educação Matemática. Por utilidade se entende a qualidade ou o caráter do que é útil; por sua vez, a palavra útil vem do latim utilis, formada pela palavra $u t i$, que significa "servir, poder ser usado", mais o sufixo -ilis, que significa "possibilidade", segundo afirma o Diccionario Etimológico Castellano en Línea - Decel ${ }^{1}$. Nesse sentido, a etimologia da palavra útil se remete à qualidade de poder ser usado. De modo geral, podemos concordar que o conceito de utilidade e do que é útil está relacionado à característica ou propriedade daquilo "que é meio ou instrumento para um fim qualquer" (Abbagnano, 2007, p. 987). Desse modo, cientes de que esses conceitos são essenciais a determinadas concepções filosóficas e da economia política (Abbagnano, 2007), atemo-nos à abordagem do referido conceito no âmbito da Educação Matemática, buscando aprofundar o debate com base na abordagem feita por Spacek (2017).

Como ponto de partida, é necessário destacar que aquilo que é considerado útil em Educação depende da perspectiva teórica que assumimos. Assim, o útil pode assumir diferentes vieses, influenciando e sendo influenciado pelos fins da atividade de ensino, a seleção de conteúdo e a forma de estruturação do currículo, bem como a própria função da escola. No presente artigo, partimos da premissa de que, muitas vezes, o que é considerado útil parte da finalidade posta para o ensino de determinado conteúdo, o qual, por sua vez, também influencia de modo interrelacionado a proposição dessa finalidade.

Em um contexto amplo há, de acordo com Ordine (2016, p. 9), uma tendência a considerar todos aqueles conhecimentos humanísticos e, de modo geral, todos aqueles que não estão circunscritos na esfera da produção econômica como sendo inúteis. Como consequência, podemos inferir que a lógica do mercado de trabalho solapa as bases das instituições educacionais e que disciplinas as quais não se desenvolvem a partir da produção de valor econômico imediato não possuem utilidade, sendo consideradas menos importantes. Conforme Ordine (2016), esse contexto no qual as ideias dominantes põem o conceito de utilidade a serviço dos interesses das classes dominantes

[...] está progressivamente matando a memória do passado, as disciplinas humanísticas, as línguas clássicas, a educação, a livre pesquisa, a fantasia, a arte, o pensamento crítico e o horizonte civil que deveria inspirar toda atividade humana. No universo do utilitarismo, um martelo vale mais que uma sinfonia, uma faca mais que um poema, uma chave de fenda mais que um quadro: porque é fácil compreender a eficácia de um utensílio, enquanto é sempre mais difícil compreender para que podem servir a música, a literatura ou a arte (Ordine, 2016, p. 12).

\footnotetext{
${ }^{1}$ Disponível em http://etimologias.dechile.net/.
} 
Essa concepção da categoria utilidade também se faz presente nos discursos pedagógicos que dicotomizam as categorias prática e teoria, acentuando a primeira em detrimento da segunda, bem como aquelas que valorizam os conhecimentos oriundos das atividades prático-utilitárias que emergem do cotidiano das crianças (Giardinetto, 1999). É possível compreender que essas formas de entendimento têm origem na cisão pragmatista entre as categorias prática e teoria, como se houvesse uma cisão técnica entre ambas. Isso traz consequências diversas, dentre as quais podemos destacar as políticas de formação docente, que sofrem os efeitos do chamado recuo da teoria (Moraes, 2001) no âmbito educacional, como também das concepções subjacentes ao ensino dos próprios professores (Spacek, 2012; Spacek \& Ortigara, 2018).

Outra concepção que apresenta elementos para a compreensão do conceito de utilidade é a teoria do cotidiano de Ágnes Heller $^{2}$. A autora indica a existência de duas esferas da vida humana, que possuem aspectos distintos, apesar de não possuírem limites rígidos. São elas a esfera da vida cotidiana e a esfera da vida não cotidiana (Heller, 2002). O parâmetro que a autora utiliza para distinguir essas duas esferas é o da reprodução do indivíduo e da sociedade. As atividades voltadas diretamente à reprodução do indivíduo que, indiretamente, direcionam-se para a reprodução da sociedade são chamadas de atividades cotidianas. Aquelas que diretamente se orientam à reprodução da sociedade e, indiretamente, voltam-se à reprodução do indivíduo são denominadas atividades não cotidianas.

Uma das características da vida cotidiana é a heterogeneidade, enquanto a homogeneidade é característica da esfera da vida não cotidiana. Segundo Netto (1987, p. 66, itálicos no original), a heterogeneidade e a imediaticidade da vida cotidiana "implicam que o indivíduo responda levando em conta o somatório dos fenômenos que comparecem em cada situação precisa, sem considerar as relações que os vinculam". Portanto, a cotidianidade exige respostas funcionais às situações sem que, necessariamente, o indivíduo tenha ciência do conhecimento interno ou das relações que estabelecem os fenômenos entre si. Nesse viés, a utilidade assume, no cotidiano, um papel de critério de verdade.

A partir desse contexto, o ensino da Matemática estaria voltado à socialização apenas daqueles conteúdos que emergiriam das atividades cotidianas, bem como daqueles em que se pode observar um caráter dito útil por meio de sua aplicação em processos produtivos técnicos. Isso ocorre uma vez que nem todos os conceitos matemáticos apresentam fins imediatos e econômicos em um primeiro momento ou aplicações práticas na vida cotidiana, sendo acentuados, na escola, aqueles conhecimentos e aquelas habilidades necessários para a existência imediata dos sujeitos na vida cotidiana, ou seja, aqueles que são oriundos de necessidades imediatas.

Esse posicionamento contraria o caráter científico que a escola assume atualmente, pois não coloca os estudantes para além de sua atuação cotidiana, não engendrando a necessidade de apropriação de conhecimentos científicos elaborados histórica e socialmente, que possibilitam uma apropriação cada vez mais aproximada do movimento da realidade. Nesse sentido, conforme Spacek (2012), o motivo e a finalidade da atividade de ensino, assim como os fins de suas ações, sofrem forte influência de perspectivas pragmático-utilitárias.

Com base nesse contexto, o problema de pesquisa se expressou no seguinte questionamento: como a categoria utilidade é entendida no âmbito da Educação Matemática a partir do prisma da Pedagogia Histórico-Crítica? Assim, o objetivo foi compreender a categoria utilidade no campo de estudos da Educação Matemática, de modo especial, a partir das bases teóricometodológicas que fundamentam a Pedagogia Histórico-Crítica.

\section{Considerações Metodológicas}

A presente pesquisa, de cunho bibliográfico, buscou discutir a categoria utilidade no campo de estudos em Educação Matemática a partir das bases teórico-metodológicas que fundamentam a Pedagogia Histórico-Crítica. Para tal, lançamos mão

\footnotetext{
2 Ágnes Heller (1929 - 2019) foi uma filósofa húngara.
} 
de uma revisão de literatura que proporcionou uma análise do objeto da pesquisa. Assim, foi possível fazer as mediações necessárias entre a referida categoria e as discussões acerca de sua influência no ensino de Matemática. Pata tal, focamos numa abordagem qualitativa, uma vez que esta "[...] corresponde a um espaço mais profundo das relações, dos processos e dos fenômenos que não podem ser reduzidos à operacionalização de variáveis” (Minayo, 2002, p. 22).

Quanto aos objetivos, a pesquisa se classifica como exploratória, pois, segundo Gil (2002, p. 41), "estas pesquisas têm como objetivo proporcionar maior familiaridade com o problema, com vistas a torná-lo mais explícito ou a constituir hipóteses. Pode-se dizer que estas pesquisas têm como objetivo principal o aprimoramento de idéias [sic] ou a descoberta de intuições". Assim, buscamos aprofundar a temática da categoria utilidade a fim de desenhar uma análise sobre a compreensão utilitáriopragmatista e dialético-materialista no campo da Educação Matemática.

Com base nas reflexões sobre tal categoria, tomamos como fundamento para a pesquisa algumas obras basilares: Aleksandrov (1991), Giardinetto (2010), Heller (2002), Kosik (1976), Ordine (2016), Saviani (2008), dentre outras.

\section{Resultados e Discussão}

A literatura nos mostra que a categoria utilidade aparece de diferentes formas nas pesquisas em Educação Matemática, muitas vezes condensadas nos fins postos por cada tendência. Nesse sentido, esboçamos algumas considerações sobre o conceito de utilidade com base na Pedagogia Histórico-Crítica.

Conforme aponta Saviani (2008), a escola tem como função promover a apropriação, por parte dos estudantes, dos conhecimentos produzidos e sistematizados historicamente pela humanidade. Nesse mesmo sentido, Giardinetto (2010) busca no conceito da categoria clássico, investigado por Saviani (2008), subsídios para justificar a universalidade do conhecimento matemático e a sua necessidade para a formação do indivíduo.

O clássico, na concepção de Saviani (2008), é aquilo que se firma como essencial e fundamental, resiste ao tempo e

Define-se, pois, pelas noções de permanência e referência. Uma vez que, mesmo nascendo em determinadas conjunturas históricas, capta questões nucleares que dizem respeito à própria identidade do homem como um ser que se desenvolve historicamente, o clássico permanece como referência para as gerações seguintes que se empenham em se apropriar das objetivações humanas produzidas ao longo do tempo (Saviani \& Duarte, 2010, p. 431).

Podemos notar que tal categoria, nessa concepção, pode ser identificada como objetivação genérica ${ }^{3}$, visto que cumpre a sua função de referência para as gerações posteriores. Mas é importante destacar que o clássico, segundo Saviani (2008) e Saviani e Duarte (2010), não se confunde com o tradicional e não se opõe ao moderno. Desse modo, esse conceito pode ser, conforme já apontado acima, central na educação escolar, em sentido stricto, já que, segundo Saviani (2008), uma das funções dessa forma de educação é a transmissão do conhecimento considerado clássico. Esse processo visa à humanização dos indivíduos, ou seja, à apropriação pelos indivíduos das máximas capacidades humanas, com a finalidade de tornarem-se capazes de apreender o movimento do real, proporcionando, desse modo, uma atuação mais efetiva e livre ante essa realidade.

No caso da Matemática, clássico "é a ampliação dos campos numéricos, a álgebra, a geometria, a trigonometria, a análise combinatória, enfim, os conteúdos matemáticos que hoje compõem a grade curricular de Matemática dos anos escolares" (Giardinetto, 2010, p. 760). E, por que são fundamentais esses conceitos? Por dois pontos citados por Duarte (2001).

\footnotetext{
${ }^{3}$ Para Heller (2002, pp. 380-381, itálicos no original), "la actividad, el comportamiento, etcétera, del hombre se objetivian siempre. Pero no todo objetivarse implica una objetivación. Ante todo, las objetivaciones son siempre genéricas y encarnan distintos tipos de generecidad. Además éstas no sons implemente las consecuencias de acciones exteriorizadas, objetivadas, sino sistemas de referencia que, respecto a las actividades del hombre que se orientan hacia ellos y que los plasman, son externos. El hombre particular deve, por tanto, apropiárse-las para que las objetivaciones se remitan a el y el las pueda plasmar. Y si cada uno puede apropiárselas relativamente al mismo nível, no todas las objetivaciones pueden ser formadas, plasmadas por nadie al mismo nível".
} 
Primeiramente, são indispensáveis ao indivíduo, pois esses conteúdos se incorporam cada vez mais no cotidiano e, em segundo lugar, porque são necessários à reprodução social para a sustentação das ciências e dos patrimônios do gênero humano, que garantem a transformação da natureza para a satisfação das necessidades humanas.

Não é possível à sociedade ter novos engenheiros, médicos, cientistas, educadores, arquitetos, mecânicos, etc. em suas diversas áreas, sem a apropriação daquilo que é "clássico" em matemática (e nos demais saberes escolares) e que forma engenheiros, médicos, cientistas, educadores etc (Giardinetto, 2010, p. 761).

Nesse sentido, partindo da Pedagogia Histórico-Crítica, podemos considerar que a categoria utilidade, no âmbito da Educação Matemática, manifesta-se na relação entre indivíduo-sociedade-gênero. Essa relação não se concretiza de maneira imediata por meio de uma necessidade individual, mas por uma relação mediada pelas necessidades individual e genérica de reprodução do gênero humano no processo de reprodução social. Desse modo, os conhecimentos matemáticos considerados úteis no contexto imediato da vivência dos indivíduos no contexto atual não são suficientes para a produção, nos indivíduos, das máximas potencialidades humanas, bem como ao processo de reprodução do gênero e da sociedade, sendo necessários a socialização e a apropriação daqueles considerados clássicos. No entanto, devido ao processo de divisão social do trabalho que impera na atual forma de sociabilidade, produz-se um processo que proporciona modos de vida os quais, por um lado, engendram, em uma parcela menor dos indivíduos, necessidades vinculadas ao gerenciamento da atual ordem social e que exigem a apropriação de conhecimentos mais complexos e ricos em determinações. Por outro lado, produzem, na maior parte dos indivíduos, necessidades que se voltam apenas à reprodução individual ${ }^{4}$. Portanto, para essa parcela da população, a sua existência se reproduz a partir das vinculações mais imediatas limitadas às suas condições, em que os conhecimentos adquirem utilidade nessas vinculações.

Nesse contexto, é importante destacar que "a práxis utilitária cotidiana cria 'o pensamento comum' - em que são captados tanto a familiaridade com as coisas e o aspecto superficial das coisas quanto a técnica de tratamento das coisas - como forma de seu movimento e de sua existência" (Kosik, 1976, p. 15, itálico no original). Assim, essa práxis utilitária não pode ser concebida como ponto de chegada, mas estritamente como ponto de partida ineliminável do processo de conhecimento da realidade. Isto é, o caráter útil de determinado conhecimento não pode ser considerado a partir desses limites, uma vez que é necessário, para a apreensão de determinado objeto, avançar para além da "familiaridade" e do "aspecto superficial" do objeto, buscando apreendê-lo em sua essência e em movimento. Essa visão se explicita também à concepção de Matemática.

Conforme Jardinetti (1997, p. 49), a Matemática é uma "ciência das relações" e, por consequência, com o movimento histórico da elaboração do conhecimento matemático, apesar de ser gerado por necessidades econômica e social, desvencilha-se da realidade imediata e é construída a partir de sua própria base. "A reflexão abstrata frequentemente vai além das necessidades imediatas de um problema prático" (Aleksandrov, 1991, p. 37, tradução nossa) ${ }^{5}$. Nesse sentido, a relativa autonomia da produção do conhecimento matemático em relação à realidade material não a torna uma ciência do pensamento puro, assim como, tampouco, coloca-a em uma condição de indissociação estrita com realidade física.

Assim, é importante destacar que, ao analisarmos a concepção de utilidade intrínseca à Pedagogia Histórico-Crítica, não estamos advogando por um ensino que esteja pautado em uma Matemática totalmente desvinculada dos processos de produção e reprodução material da sociedade. Tampouco defendemos a Matemática composta por objetos e entes abstratos existentes objetivamente em uma realidade paralela independentemente dos seres humanos na qual a finalidade de seu ensino e, portanto, sua utilidade, se reduziriam ao desenvolvimento do raciocínio e do pensamento lógico. Nossa intenção é problematizar o extremo oposto, ou seja, a redução da importância dos conhecimentos matemáticos à sua aplicação à realidade imediata dos

\footnotetext{
${ }^{4}$ Importante destacar que aqui estamos lidando com um processo tendencial e não determinado.

${ }^{5}$ No original lê-se: "La reflexión abstracta a menudo vá más lejos que las necesidades inmediatas de un problema práctico".
} 
indivíduos, ou seja, uma perspectiva cuja utilidade se restringe ao âmbito da vida cotidiana e da vivência imediata dos indivíduos.

Essa apologia à redução da importância do conhecimento matemático à sua aplicação sugere uma postura utilitáriopragmatista ante essa ciência. Ou seja, a necessidade intrínseca a esse campo de conhecimento seria limitada às aplicações práticas imediatas, em detrimento, por exemplo, das aplicações teóricas ou aplicações que exigiriam cadeias de mediações, afastando-se das atividades e dos processos de utilização cotidianos. As primeiras são mais imediatistas no que tange à cotidianidade dos indivíduos, pois apelam às relações conceituais com objetos físicos. Já as segundas aparecem em níveis mais elevados de produção do conhecimento, portanto, mais complexos e ricos em mediações. Assim, "não somente a compreensão da Matemática como inerente a [sic] realidade física, mas também a constante aplicabilidade imediatista que fazemos com seus conceitos, contribui para a apreensão mecanicista dessa ciência" (Candiotto, 2016, p. 126).

Esse tipo de apreensão acaba por reduzir a categoria utilidade às aplicações utilitário-pragmatistas citadas anteriormente. Essas reduções expulsam as relações dialéticas intrínsecas à produção do conhecimento matemático, pois não consideram a produção da satisfação das necessidades humanas nas esferas da vida cotidiana e não cotidiana.

Assim, podemos considerar que a utilidade da Matemática, sob o prisma da Pedagogia Histórico-Crítica, caracteriza-se pela importância dessa ciência para o desenvolvimento humano em um sentido mais amplo. Seu valor de verdade aparece na necessidade de reprodução do gênero humano, não apenas na criação de valor econômico, apesar de, em certa medida, possuir esse caráter.

Esse debate esbarra nas questões econômicas, uma vez que, hegemonicamente, as instituições educacionais pautam as finalidades da educação escolar em uma formação para o mercado de trabalho. Tal postura se torna um obstáculo no processo de apropriação dos conhecimentos científicos para o desenvolvimento do pensamento teórico por parte dos estudantes uma vez que sua finalidade se fundamenta no domínio de técnicas matemáticas para a execução de atividades profissionais. É importante, nesse contexto, a contribuição de Machado (2009, p. 94-95) ao afirmar que

[...] os trabalhadores que não são intelectuais precisam conhecer um número cada vez maior de técnicas e ferramentas matemáticas. Não é necessário que produzam Matemática, mas é fundamental que saibam utilizá-la eficientemente. A utilização refere-se ao domínio das múltiplas técnicas das quais, na imensa maioria das vezes, se desconhece a gênese. Em decorrência desta impossibilidade de compreender os fundamentos do que se faz, acentua-se a postura de reverência, a sensação de impotência que impede qualquer possibilidade uma postura crítica.

O domínio das técnicas, de acordo com o autor, acaba por excluir a necessidade de conhecimento da gênese e dos nexos conceituais, bem como do desenvolvimento histórico que promoveu a produção de tais conhecimentos. Desse modo, a utilidade dos conhecimentos se desvincula do seu processo de produção, estabelecendo-se - os conhecimentos - ou como entes abstratos atemporais desvinculados de toda e qualquer forma de existência e de práticas sociais, ou como conhecimentos e saberes que surgem espontaneamente nas atividades mais corriqueiras dos indivíduos, conforme Giardinetto (1999) identifica nas concepções intrínsecas a determinadas pesquisas em Educação Matemática.

Por outro lado, se buscamos uma Educação Matemática que seja útil no sentido de humanização dos indivíduos e produção das máximas potencialidades criadas historicamente e objetivadas enquanto gênero humano, é necessário que se busque no desenvolvimento histórico e lógico dos conceitos sua gênese e desenvolvimento para que seja possível que os indivíduos se apropriem deles enquanto movimento a partir das necessidades humanas que impulsionaram seu desenvolvimento.

Desse modo, é possível superar tanto as concepções a-históricas de conhecimento da Matemática, como as espontaneístas. "O pressuposto é que a análise histórica da Matemática possibilita a compreensão da sua complexificação no curso do desenvolvimento das forças produtivas e cujas necessidades também delineia" (Candiotto, 2016, p. 126). Assim, as características de uma educação escolar pautada no viés utilitário-pragmatista inviabilizam a possibilidade de uma educação voltada à formação do pensamento teórico. 
Uma perspectiva crítica de educação deve prescindir de uma visão utilitário-pragmatista que vincula a utilidade da Matemática à sua usabilidade na esfera da vida cotidiana. Assim, tal perspectiva necessita buscar, na educação escolar, fazer a mediação entre a esfera cotidiana e a não cotidiana por meio da apropriação, pelo indivíduo, dos conhecimentos que não necessariamente estejam vinculados diretamente a uma aplicabilidade na sua vida cotidiana (Duarte, 2001; Giardinetto, 1999).

Giardinetto (1999), ao analisar a concepção de conhecimento presente em determinadas tendências que supervalorizam o saber cotidiano, afirma que existe, muitas vezes, uma correlação entre o natural e o espontâneo como sendo sinônimos do que está presente no indivíduo desde seu nascimento. Isso se desdobra no entendimento de que, na educação escolar, seria necessário o aproveitamento do que é natural e espontâneo sem uma maior problematização desses aspectos, devido a sua própria natureza. Como justificativa, aparece uma supervalorização daqueles conhecimentos matemáticos adquiridos em atividades não escolares, sendo estes considerados mais livres que àqueles adquiridos na escola. Desse modo, a escola deveria, para que fosse mais eficiente, seguir a mesma lógica da apropriação de conhecimentos fora do espaço escolar. Nesse sentido, a não diretividade, bem como uma concepção negativa sobre o ato de ensinar, passaria a ser preponderante à essas concepções (Duarte, 1998). Entretanto, Giardinetto (1999, p. 65, itálicos no original), ao analisar uma situação de apropriação de conhecimentos matemáticos na atividade de trabalho, afirma que:

é preciso considerar que esse conhecimento matemático, apropriado pelo indivíduo dentro da sua atividade, de seu trabalho, é determinado pela lógica prático-utilitária inerente a essa atividade, dentro de determinado contexto, e serve determinado objetivo específico imposto, pelas circunstâncias de trabalho, ao indivíduo. A sua resposta ao troco, por exemplo, só pode ser uma - a certa. Ele não tem escolha. É a lógica autoritária e exploradora que garante a eficácia da resposta. Essa lógica não é utilizada conscientemente pelo indivíduo, mas é, como acabou de ser dito, imposta pela obrigação do indivíduo em dar não uma resposta, e, sim, somente aquela que se mostra eficaz para a atividade que desenvolve.

Ou seja, caso a educação escolar reproduza situações e atividades da vivência imediata dos estudantes, frequentemente terá como critério de utilidade para o ensino a lógica utilitário-pragmatista. É preciso, portanto, que, como temos visto, o ensino se mostre como uma alternativa para a superação dessa lógica, na medida em que permita aos estudantes o estabelecimento de relações não imediatas com sua vida. Nesse sentido, "a aprendizagem escolar se traduz na possibilidade efetiva da criança, do indivíduo, romper os limites da utilização de referenciais pragmáticos e utilitários.” (Giardinetto, 1999, p. 69).

\section{Considerações Finais}

Esta pesquisa buscou analisar como a categoria utilidade tem sido compreendida no campo de estudos da Educação Matemática. Isso pode nos revelar indícios das possíveis implicações na concepção de ensino de Matemática nas instituições educacionais.

Por meio dos fundamentos da Pedagogia Histórico-Crítica, verificamos que a utilidade não é vista no sentido imediato, mas pela relação que se estabelece entre indivíduo-sociedade-gênero. Nesse sentido,

A exigência é por uma clarificação da relação entre os conceitos matemáticos e o movimento da realidade material. O distanciamento das abstrações matemáticas em relação à realidade material é necessário. Porém, a cristalização dessas abstrações ao não percorrer o caminho de volta transforma a matemática em uma ciência que independe da realidade material, isto é, em uma ciência do pensamento puro. Por isso, Gerdes (2008) enfatiza que, para Marx (1983), a Matemática só é significante e relevante quando reflete os processos da realidade material (Candiotto, 2016, p. 105).

No caminho oposto a esse, observamos tendências utilitário-pragmatistas que imputam ao conhecimento matemático uma essência pautada na imediaticidade da vida cotidiana. A partir desse viés, corre-se o risco de transformar a Matemática em uma ciência de meras aplicações práticas, ou seja, torná-las critério de verdade dos conceitos matemáticos. Tal postura contradiz 
o percurso de seu desenvolvimento, uma vez que essa ciência se constituiu, ao longo da história da humanidade, oscilando entre o surgimento de novos conceitos a partir de necessidades práticas e a partir das próprias concatenações em sua estrutura interna.

A necessidade de um debate que se paute na gênese e no desenvolvimento histórico dos nexos conceituais dos conhecimentos matemáticos é urgente e pressupõe, a partir do nosso entendimento, uma interpretação dialético-materialista. A intenção é instigar as discussões com a finalidade de aprimorar o desenvolvimento da práxis pedagógica que tenha como fundamento uma formação humana omnilateral.

Em suma, consideramos importante a continuação do debate sobre a categoria utilidade, seja no âmbito da Educação Matemática, seja naquelas áreas de pesquisa relacionadas ao ensino de outros conjuntos de conhecimentos. No que se refere ao âmbito da Educação Matemática, é imprescindível que se avance no sentido de compreender como essa categoria é entendida e como ela aparece nas demais tendências, ou seja, para além da Pedagogia Histórico-Crítica. Também, consideramos premente a necessidade de um maior aprofundamento teórico sobre a própria categoria utilidade, bem como sua correlação com outras, como por exemplo, com o par categorial prática e teoria.

\section{Agradecimentos}

O presente trabalho foi realizado com o apoio da Coordenação de Aperfeiçoamento de Pessoal de Nível Superior Brasil (CAPES) - Código de Financiamento 001.

\section{Referências}

Abaggnano, N. (2007). Dicionário de filosofia. Martins Fontes.

Aleksandrov, A. D. (1991). Visión general de la matemática. In: Aleksandrov, A. D. et al. La matemática: su contenido, métodos y significado. Alianza.

Candiotto, W. C. (2016). Crítica da razão matemática: uma análise do objeto da Geometria. Tese de Doutorado, Universidade Federal de Santa Catarina, Florianópolis, SC, Brasil.

Diccionario Etimológico Castellano en Línea - Decel. Etimología de útil. Última actualización enero 2021. Recuperado de: http://etimologias.dechile.net/?u.til. Acceso en: 10 enero 2021.

Duarte, N. (2001). Educação escolar, teoria do cotidiano e a escola de Vigotski. Autores Associados.

Duarte, N. (1998). Concepções Afirmativas e Negativas sobre o ato de ensinar. Cadernos Cedes. Campinas, 19(44), 85-106.

Giardinetto, J. R. B. (1999). Matemática Escolar e Matemática da Vida Cotidiana. Autores Associados.

Giardinetto, J. R. B. (2010). O Conceito de Saber Escolar “Clássico” em Demerval Saviani: Implicações para a Educação Matemática. Bolema, 23 (36), 753773.

Gil, A. C. (2002). Como elaborar projetos de pesquisa. Atlas.

Heller, Á. (2002). Sociología de la Vida Cotidiana. Ediciones Península.

Jardinetti, J. R. B. (1997). O abstrato e o concreto no ensino da Matemática: algumas reflexões. Bolema, 11 (12), $45-57$.

Kosik, K. (1976). Dialética do Concreto. Paz e Terra.

Machado, N. J. (2009). Matemática e realidade: análise dos pressupostos filosóficos que fundamentam o ensino de matemática. Cortez.

Minayo, M. C. S. (2002). Pesquisa social: teoria método e criatividade Vozes.

Moraes, M. C. M. (2001). Recuo da teoria: Dilemas da pesquisa em educação. Revista Portuguesa de Educação, 14 (01), 07-25.

Netto, J. P. (1987). Para a Crítica da Vida Cotidiana. In: M. C. Falcão \& J. P. Netto (Orgs.). Cotidiano: conhecimento e crítica. São Paulo: Cortez.

Ordine, N. (2016). A utilidade do inútil: um manifesto. Zahar.

Saviani, D. \& Duarte, N. (2010). A Formação Humana na Perspectiva Histórico-Ontológica. Revista Brasileira de Educação, 15 (45), $422-433$.

Saviani, D. (2008). Pedagogia Histórico-Crítica: Primeiras Aproximações. Autores Associados. 
Research, Society and Development, v. 10, n. 2, e32410212676, 2021

(CC BY 4.0) | ISSN 2525-3409 | DOI: http://dx.doi.org/10.33448/rsd-v10i2.12676

Spacek, I. K. (2012). A Relação entre Atividade de Ensino de Matemática e a Formação da Individualidade Discente. Dissertação de Mestrado, Universidade do Extremo Sul Catarinense, Criciúma, SC, Brasil.

Spacek, I. K. (2017). A Utilidade do Ensino de Matemática subjacente nas Tendências em Educação Matemática. In: II Seminário de Filosofia e Sociedade, 2017, Criciúma. Filosofia e Sociedade.

Spacek, I. K. \& Ortigara, V. (2018) A concepção de formação do indivíduo subjacente à finalidade da atividade de ensino de professores de matemática. Educação e Cultura Contemporânea, 15 (38), 115-140. 